Article

\title{
Designing Difference: Co-Production of Spaces of Potentiality
}

\author{
Garrett Wolf ${ }^{1, *}$ and Nathan Mahaffey ${ }^{2}$ \\ ${ }^{1}$ Manchester Architecture Research Centre, The University of Manchester, M13 9PL, Manchester, UK; \\ E-Mail: garrett.wolf@postgrad.manchester.ac.uk \\ ${ }^{2}$ Development Planning Unit, University College London, WC1H 9EZ, London, UK; \\ E-Mail: nathan.mahaffey.12@ucl.ac.uk \\ * Corresponding author
}

Submitted: 5 January 2016 | Accepted: 7 March 2016 | Published: 22 March 2016

\begin{abstract}
Design and Planning professionals have long been influenced by the belief in physically and spatially deterministic power over people and the environment, a belief that their representations of space become space. As a result the goal of design often becomes "fixing" or directing behavior and culture instead of letting culture happen. This outlook often prevents designers from engaging critically with culture, through representational space and spatial practice, as a crucial, possibly the most crucial, aspect in the design process. Just as human cultures interact to constantly reproduce and co-produce hybrid cultures, the professional designer and those users and experiencers of design (at whatever scale) must interact to co-produce spaces and places of activity. Through a critique of the practice of placemaking, we highlight the need to differentiate between participation and co-production. Understanding participation as one element of the design process and the role of design at larger scales of co-productive processes can help designers have a better understanding of how spaces are produced, and the role of designers in the creation of spaces of potentiality. Agamben's writing on potentialities and Lefebvre's spatial triad offer a theoretical framework to investigate the ethical role of professional designers in society while taking a critical stance against the singular solutions of modernist urban transformation. Spaces of Potentiality are seen here as a designer's simultaneous withdrawal from rational problem solving and deterministic solutions, and an engagement with open source strategies for the co-production of urban space.
\end{abstract}

\section{Keywords}

Agamben; autogestion; co-production; differential space; Lefebvre; potentiality; spatial triad

\section{Issue}

This article is part of the issue "Urban Forms and Future Cities", edited by Luca D'Acci (Erasmus University Rotterdam, The Netherlands), Tigran Haas (KTH Royal Institute of Technology, Sweden) and Ronita Bardhan (Indian Institute of Technology Bombay, India).

(C) 2016 by the authors; licensee Cogitatio (Lisbon, Portugal). This article is licensed under a Creative Commons Attribution 4.0 International License (CC BY).

\section{Introduction}

Design and Planning professionals have long been influenced by the belief in physically and spatially deterministic power over people and the environment, a belief that their representations of space become space. As a result the goal of design often becomes "fixing" or directing behavior and culture instead of letting culture happen. This outlook often prevents designers from engaging critically with culture, through representational space and spatial practice, as a crucial, possibly the most crucial, aspect in the design process.

Just as human cultures interact to constantly reproduce and co-produce hybrid cultures, the professional designer and those users and experiencers of design (at whatever scale) must interact to co-produce spaces and places of activity. Through a critique of the practice of placemaking, we highlight the need to differentiate between participation and co-production. Understanding participation as one element of the design process and the role of design at larger scales of co-productive processes can help designers have a better understanding 
of how spaces are produced, and the role of designers in the creation of spaces of potentiality.

Placemaking, while having existed for several decades, has become the term $d u$ jour, for the expression of new urbanist strategies. However, it is simply the newest iteration in a line of new urbanist "processes" which harness the production of abstract space. Placemaking is a contradictory process that despite claiming to "make" place and have transformative properties actually serves to dominate and homogenize spaces through generalized rules independent of context. These generalized rules and the common perspective amongst designs and planners that behavior and activity can be controlled through the physical environment can be linked to behaviorist ideas of space and a deeper environmental determinism. As scholars once believed that environments produced cultures and individuals, designers often fall into the same trap, believing that they can control people's' movements and behaviors. These ideas can be traced to ideas of the Chicago School of Sociology, which had a profound impact on how designers and planners understood cities, and the influence of space on people (Wolch, Pincetl, \& Pulido, 2001).

When you have designer (or planner or developer) driven processes, even when they include collaboration and engagement, the spaces that are produced are all rooted in the professional perspective of designer, this means both in the case of the individual designer, but also the shared outlook of the field of design. As a result of space being constantly produced (and reproduced) from this perspective, you get space that tends towards homogeneity, that shares the characteristics thought, by the designer, to be important either to design or the community. Only when design can reach the production of space through co-production, with the community or user group as equal partner in the creation of knowledge about a place, the role of the knowledge in design, and design itself. If this engagement can be seen as between a designer and a community, both possess necessary knowledge for production that the other does not, it is a recognition of the importance of these knowledges and respect for them that allows co-production to occur. Through this coproduction, designers can avoid the pitfalls of practices such as placemaking by creating spaces that uniquely respond to the deep contextualization that can be achieved through the process of co-production.

The problematic of the notion of 'participatory design' embedded within hegemonic processes and 'tyranny' has been critiqued by many (Awan, Schneider, \& Till, 2011; Cooke \& Kothari, 2001; Jenkins \& Forsyth, 2010; Jones, Petrescu, \& Till, 2005; Till, 2009). Still, designers partner with the usual suspects and continue offering their (improved) services to new clients, rather than changing their services and partnerships to address underlying systemic issues. It is not our intention to promote another label or term (such as coproduction) as the new best practice or a new set of rules, but rather just the opposite, to offer a critical stance, and develop a clearer shared understanding of the intended impact of co-production, and to emphasize the need to reposition the role of design to facilitate community control over the production of space. There is also a need to differentiate between movements that claim to improve conventional processes, by merely disguising them with new tools, and those that seek to reposition their role in different processes, with different actor groups.

The coupling of Lefebvre and Agamben serves to set a point of departure for a goal and a methodology for co-production. These thinkers can be used to rethink the act of design, and intertwine critical design practice with everyday spatial practice, rather than refining technocratic problem solving and delivery of solutions. By simultaneously withdrawing from the "potential to actualize" and engaging with the creation of "spaces of potentiality," the act of design becomes 1) a withdrawal from and resistance to forces of development that create inequality and exclude sections of society and 2) an engagement with dynamic, hybrid processes that enable a multiplicity of actors, other forms of knowledge, other forms of production, and other potentialities to manifest.

\section{Producing Differential Space}

The idea of space conjures a variety of images in the mind, some very clear and specific, others ethereal. In this context of the production of space, let us take space to mean the site of interaction. This image of interaction allows us to move beyond social space, because the interactions that occur within this space go beyond the social.

Lefebvre's theory on the production of space is based on his three-dimensional dialectic (Schmid, 2008). This conceptual triad is made up of conceived, perceived, and lived. Christian Schmid explains the moments of the triad as "material social practice"; "language and thought"; "and the creative, poetic act" (Schmid, 2008, p. 33). This is Lefebvre's understanding of social reality, and he applies it to a variety of fields, most famously space. Each part of the conceptual triad is a moment in the process of creation of social reality (Lefebvre, 1974/1991). Lefebvre translates his conceptual triad into spatial terms to explain the production of space: spatial practice, representations of space, and spaces of representation. This spatial triad links these three moments, which interact to produce space.

Spatial practice is the interaction of a person or thing with other people and things. This interaction is influenced by the context of the interaction. Spatial practice is the negotiation of physical space, "space 
that is generated and used". This negotiation is a society "deciphering" space. This deciphering of space is linked to physical form people's perceptions of daily and urban reality. These spatial practices structure "daily routine" and "the routes and networks which link up the places set aside for work, 'private' life and leisure" (Lefebvre, 1974/1991, p. 38). This structure "ensures societal cohesion, continuity, and a specific spatial competence" (Merrifield, 1993, p. 524). For Lefebvre, this space is concrete, material, physical, or real space.

Representations of space are conceptualizations of space. Spaces represented on paper through plans, maps, and mathematics. This also equates to mental space, space that is conceived by those with knowledge and power, to be imposed. For Lefebvre this is the space of architects, planners, engineers, urbanists, and technocrats. "This is the dominant space in any society (or mode of production)" (Lefebvre, 1974/1991, p. 39) and is "intimately tied to relations of production and to the 'order' those relations impose, and hence to knowledge, to signs, to codes, to 'frontal' relations" (Lefebvre, 1974/1991, p. 33). This is Lefebvre's abstract, mental, geometric, or imagined space.

Representational space is the space of everyday life. This space is directly lived by 'inhabitants' and 'users' through "associated images and symbols" (Lefebvre, 1974/1991, p. 39). As representations of space are dominant, so representational spaces are dominated. Lived space is the site of informal local knowledge, because this knowledge is elusive, those who conceive space seek to master and control it (Elden, 2004; Merrifield, 2006).

Andy Merrifield reminds us that "relations between conceived-perceived-lived spaces aren't ever stable, nor should they be grasped artificially or linearly" (Merrifield, 2006, p. 111). This is important lest we forget the perpetual dynamism of the production of space and the dialectical relationship amongst the three moments of the spatial triad. The spatial triad is not a precise formula, but rather an analytical method for how space is produced in historico-socio-geographic context.

"Lefebvre has been around long enough to know that lived experience invariably gets crushed and vanquished by the conceived" (Merrifield, 2006, p. 111). So, why is this important? Stuart Elden explains it well:

"Concrete space is the space of gestures and journey's of the body and memory, of symbols and sense. This concrete content, of time inscribed in a space is misunderstood by reflexive thought, which instead resorts to the abstract space of vision, of geometry. 'Abstract space is measurable' (Lefebvre, 1970/2003). Architects and urbanists work with this abstract space, this paper space of drawings, and are divorced from the level of the 'lived' in a dual sense. This is because, as well as abstracting from it in their understanding, they then project this understanding back onto the lived level. As Lefebvre notes, the plan does not rest innocently on paperon the ground it is the bulldozer that realizes these 'plans'. 'Space has long ceased to be a passive geographic or empty geometric milieu. It has become instrumental' (Lefebvre, 1970/2003).

In order to make progress in understanding space we need to grasp the concrete and abstract together. As Lefebvre argued in Dialectical Materialism, if only one is grasped and turned into an absolute, a partial truth becomes an error: 'By rejecting a part of the content it gives sanction to and aggravates the dispersion of elements of the real' (Lefebvre, 1970/2003). Just as Lefebvre described the state as a 'realized abstraction' (Lefebvre, 1976, p. 67), space too is a realized (in both senses of the word) abstraction. Here there is a balance struck-a dialectical relation-between idealism and materialism. Space is a mental and material construct. This provides us with a third term between the poles of conception and perception, the notion of the lived." (Elden, 2004, pp. 189-190)

As Lefebvre states, and as evidenced by The Production of Space there are a multitude of spaces. In addition to the spatial triad, and in the context of the argument for a co-production of spaces of potentiality, abstract and differential space are particularly relevant, helping to illustrate the space that has resulted from the predominant production of space today, and how space may be produced differently.

Abstract space is real space generalized or abstracted, the materializations of the domination of conceived space (Merrifield, 2006). Ideas of abstract space are influenced by behaviorist ideas of space, that space can control people's movements and behavior. This understanding is influenced by traditions of environmental determinism and ideas of the Chicago School of Sociology (Wolch et al., 2001). This manifests in two ways in design and planning. First through the "expertise" of the designer as the possessor of knowledge, and second through the designer as creator, who will use that knowledge to influence people and behavior. In this way, abstract space is particularly interesting because it acts both negatively and positively. It acts negatively by destroying difference, by attempting to homogenize all manner of spaces. Abstract space also acts positively, because it produces something new, replacements for the various spaces that it generalizes (Lefebvre, 1974/1991; Stanek, 2008, 2011). Abstract space is highly complex, and with complexity there can appear contradictions. Within these contradictions lies the opportunity to combat and resist abstraction. 
"The reproduction of the social relations of production within this space inevitably obeys two tendencies: the dissolution of old relations on the one hand and the generation of new relations on the other. Thus, despite-or rather because of-its negativity, abstract space carries within itself the seeds of a new kind of space. I shall call that new space 'differential space', because, inasmuch as abstract space tends towards homogeneity, towards the elimination of existing differences or peculiarities, a new space cannot be born (produced) unless it accentuates differences." (Lefebvre, 1991, p. 52)

This is the opportunity presented to those involved in the creation of space. The inherent opportunity created by abstract space in its attempt to homogenize and control, can be seized upon to create and inject spaces of difference. It is the job of the designer to understand the abstract space and strive to analyze perceived and lived space to create the spaces of potentiality. Spaces of potentiality directly contradict the ideas of homogeneity through co-production with people and material acting and interacting with and within the everyday. ${ }^{1}$

Differential space resists homogenization because instead of being dominated by conceived space, it is rather lived space that dominates the production of differential space. Lived space helps to produce the dynamic uniqueness that people produce in the everyday. This underpins Lefebvre's idea of the right to difference. This right to difference is the right to resist generalization, the right to not be forced into categories or spaces which attempt to fix and homogenize (Lefebvre, 1974/1991; Lefebvre, 1970/2003; Milgrom, 2008). Understanding this "difference" is important to how designers and planners can participate in the coproduction of differential spaces, which necessarily involves constant co-creation of design and planning ideas and goals with those in lived space, and the resistance to homogenization.

The right to difference is a powerful architectural thought, which can be understood through the spatial triad and how space is produced. By seeing differential spaces as a goal of the design process, designers can seek to turn sites of domination into sites of resistance. Using co-production to actively achieve spaces of difference, can help lead to the architectural autogestion of a community, and the continuous potentiality of a community's space. Lefebvre argues that autogestion can serve to resist homogenization, and thus produce differential space at a variety of scales (Brenner \& Elden,

\footnotetext{
${ }^{1}$ The everyday is a term used in the philosophical writings by Lefebvrian scholars. It is understood to mean the space and time within which people and things interact with each other. It is a conceptual description, which alludes to Lefebvre's scholarship on everyday life.
}

2009; Elden, 2004; Lefebvre, 1978/2009; Lefebvre, 1979/2009).

Autogestion is literally defined as "selfmanagement", but is better understood conceptually as "workers' control" or "grassroots democracy" (Brenner \& Elden, 2009; Brenner, Marcuse, \& Mayer, 2012; Elden, 2004; Lefebvre, 1966/2009; Lefebvre, 1979/2009). As a concept it has additional characteristics as a "process through which participants continually engage in self-criticism, debate, deliberation, conflict, and struggle" (Brenner \& Elden, 2009, p. 16). Architectural autogestion can be understood then as a community's collective management of their own space, built environment, and the conditions of its production. The constant evaluation and critique of a given space and its production, resulting from architectural autogestion also leads to the flexibility and potentiality of the space, its production, and usage.

For Lefebvre autogestion is the only way for people to appropriate or reappropriate control over their own life (Brenner \& Elden, 2009). The same applies in design and planning through the autogestion of space, or self-management of space. This autogestion of space or architectural autogestion, is grounded in people reappropriating control over the conditions of the production, and continuous reproduction, of their space. Designers can facilitate architectural autogestion through a commitment to co-production. This coproduction transfers the control over the production of space to the inhabitants of lived space and the producers of differential space. Co-production of space resists generalization, because instead of designs and plans producing a constantly homogenizing abstract space, co-produced space redistributes control of design to those that reside within the everyday life that the designs or plans are intended for. Additionally, since the inhabitants of this lived space control the production of their space, they also retain control and ownership over the continuous management and reproduction of the space. Thus, co-production can be used to ultimately achieve architectural autogestion. Lefebvre describes autogestion as an opening "toward the possible" (Lefebvre 1966/2009, p. 150). This possible, in terms of space is differential space, but it is also an understanding that space is dynamic, with constant potentiality. For Lefebvre, autogestion is not a fixed condition, but "must continually be enacted" (Lefebvre, $1979 / 2009$, p. 135). For architectural autogestion the constant potentiality of space results from the constant critique and evaluation of space through its continuous management.

It is precisely through the engagement with perceived and lived spaces, but in particular lived spaces that allows architects and planners to understand space as a whole and the production of space as a whole process. By engaging in the deeply contextual nature of perceived and lived space, designers can bet- 
ter understand the triadic dialectical relationships of the spatial triad, and use this to alter and disrupt conceived space. This understanding can help shift the production of space, to a co-production of differential lived space with the people and communities they are responsible for engaging with, helping communities achieve architectural autogestion. By engaging with the real and imagined moments of space and how they intertwine and relate; to understand the physical, mental, and symbolic spaces, the movement within and through, the relations simultaneously amongst them all is to begin to grasp the process of the production of space. By grasping this, and understanding the designer's own role in the process, not only through the conception of space, but through the analysis, understanding, and engagement with perceived and lived space, designers can escape the established production of homogeneity enacted through conceived space to abstract space and the domination of these over lived space. Through engagement not just of the concepts of perceived and lived, but the people, things, movements and places that make up perceived and lived space, designers can strive to participate in the production of spaces of difference, spaces that are not intended as a destination, but rather designed to be in process, dynamic, and constantly interacting and reproducing differential space through the moments of the spatial triad, spaces of constant potentiality.

\section{Spaces of Potentiality}

Agamben's writing on Potentialities serves not as a supplement to Lefebvre, but as a link between Lefebvre and the professional design disciplines, towards a methodology for connecting concrete and abstract space. This analytical framework explores a way to reconceptualize and reposition the role of design to deal with this dialectical relationship. This section will elaborate the notion of 'spaces of potentiality,' seen here as the result of a designer's simultaneous withdrawal from rational problem solving and deterministic solutions, and an engagement with open source strategies for the co-production of urban space.

Where Aristotle posits potentiality and actuality as interrelated opposites, Agamben ventures beyond the binary of potential/actual. Rather than viewing potential as something that becomes actual, he sought to manifest or illuminate a mode of existence of potentiality. He states that potentiality is "not simply nonBeing, simple privation, but rather the existence of non-Being, the presence of an absence" (Agamben \& Heller-Roazen, 1999, p. 179).

Agamben, rather than describe impotentiality as the privation of potentiality, expands Aristotle's logic to mean that existing in the mode of potentiality means both the potential to be and not be, "Beings that exist in the mode of potentiality are capable of their own impotentiality, and only in this way do they become potential. They can be because they are in relation to their own non-Being" (Agamben \& Heller-Roazen, 1999, p. 182). Being capable of our own impotentiality fundamentally acknowledges our ability to not act, or to be inoperative, to step out of the ever flowing current that demands production.

"Deprived of the experience of what he can not do, today's man believes himself capable of everything...precisely when he should instead realize that he has been consigned in unheard of measure to forces and processes over which he has lost all control. He has become blind not to his capacities but to his incapacities, not to what he can do but to what he cannot, or can not, do." (Agamben, 2010, p. 44)

Agamben begins to interrogate the relationship between potentiality and impotentiality by asking, "How is it possible to consider the actuality of the potentiality to not-be? The actuality of the potentiality to play the piano is the performance of a piece for the piano; but what is the actuality of the potentiality to notplay?" (Agamben \& Heller-Roazen, 1999, p. 183).

Further exploring the potentiality to not do, in the chapter entitled 'Bartleby' of The Coming Community, Agamben states that "The perfect act of writing comes not from a power to write, but from an impotence that turns back on itself and in this way comes to itself as a pure act (which Aristotle calls agent intellect)", then goes on to describe "Bartleby, a scribe who does not simply cease writing but 'prefers not to,' (...) [and] writes nothing but [his] potentiality to not-write" (Agamben, 2007, p. 36). Keeping in mind Bartleby (the scribe who does not write) and Aristotle's image of tabula rasa (the tablet in which nothing is written), we turn back to Agamben's elaboration on Aristotle's example of potentiality and thought in De Anima: "Thanks to this potentiality to not-think, thought can turn back to itself (to its pure potentiality) and be, at its apex, the thought of thought. What it thinks here, however, is not an object, a being-in-act, but that layer of wax, that rasum tabulae that is nothing but its own passivity, its own pure potentiality (to not-think): "In the potentiality that thinks itself, action and passion coincide and the writing tablet writes by itself or, rather, writes its own passivity" (Agamben, 2007, p. 36).

As Aristotle describes agent intellect as the pure act of turning a thing back on itself, can an agent architect be thought of as one who does not design and build a final outcome but rather one who becomes that layer of wax, a position of intervention between the act and the being, that all other actions must pass through? Can the architect cease to be an agent of production, to instead become an agent of design in itself-a designer of design - not as an agent of autonomous archi- 
tecture but a designer of processes and frameworks for engagement?

Here it is important to state that occupying the space of impotentiality does not mean to not build. Agamben states that "the root of freedom is to be found in the abyss of potentiality. To be free is not simply to have the power to do this or that thing, nor is it simply to have the power to refuse to do this or that thing. To be free is, in the sense we have seen, to be capable of one's own impotentiality" (Agamben \& Heller-Roazen, 1999, p. 182-183).

This speculation on a reconfigured field of design intends to say-as Melville's Bartleby did-"I would prefer not to" become complicit in hegemonic, singular processes of development and modernization, but rather that an act of design can be an act of defiance; becoming capable of our impotentiality gives us the freedom to reconfigure engagement with social, political, economic and environmental dynamics. The balance of idealism/materialism and potentiality/impotentiality is a path for designers to demonstrate both withdrawal and engagement, a methodology for co-production that does not view "co-" as merging things together, but as a defense/preservation of "otherness".

We have visited the importance of the notion of potentiality for the same reason that Agamben stated, "I think that the concept of potentiality has never ceased to function in the life and history of humanity, most notably in that part of humanity that has grown and developed its potency to the point of imposing its power over the whole planet" (Agamben \& HellerRoazen, 1999, p. 177). Acknowledging the limits of design and planning is particularly relevant today, when design is re-emerging as a global phenomenon.

Although the intention of placemaking is to promote a collaborative process to reimagine and revitalize public spaces (Project for Public Spaces, 2015), one fundamental limitation is that it accepts 'making of place' and 'construction of space' as separate processes-"Making a place is not the same as constructing a building, designing a plaza, or developing a commercial zone" (Project for Public Spaces, 2015). In other words, it often views the professional process of design as a flawed one that must be improved by a separate grassroots efforts.

\section{The Role of Design}

Design has traditionally been conceived as top-down, and occasionally bottom-up. There is a need to expand the space between these two typical modes to explore an alternative conceptual approach. The how in a conventional top-down process involves pre-planning all aspects of a project with select few actors (e.g. architect, contractor, client), whereby the end users are seen as the "recipients" who may or may not be consulted during the design process (a gap that placemaking seeks to fill). A bottom-up process is conceptually different in that it begins with individuals and community groups at a grassroots level, which incrementally solidify themselves into a larger movement that seek to affect those planning processes at the top of the hierarchy. This interplay between top-down and bottomup processes creates a cyclical frame and a dialectical relationship between design professionals and the social. In this sense, there is always 'participation' between architects and society, but when it happens is a variable that changes the impact and responsiveness of a project to its respective people and place.

Both top-down and bottom-up approaches, which position the participation by the social before or after the act of design, create a displacement between the formal and informal acts of design and production (the conceived and lived). In a top-down approach much of the decision-making is delegated to political representatives and professional experts, whom Lefebvre (1970/2003) claims do not always properly act on the behalf of those they are elected to serve. In a hierarchical system, bottom-up approaches risk becoming fragmented urban experiences, failing to influence the processes and decisions made by their representative politicians and professional experts. Additionally, Lefebvre (1970/2003) believed that active citizenship could have a significant impact on the projects, strategies and policies that shape the city, but he described one primary reason for this lack of effectiveness to be the lack of politicization of the problems. Despite efforts to fix a hierarchical system, which facilitates topdown and bottom-up design processes, it remains one that benefits a small percentage of the population at the expense of the majority, which in turn creates inequality and poverty (Peet \& Hartwick, 2009). Rather than doing what Gilbert Rist (2006) describes as fixing planning failures with more planning, there is a need to explore an alternative form of engagement between social and design processes.

To reconceptualise the space between top-down and bottom-up as 'co-production', it is necessary to explore a non-hierarchical methodology, an indirect approach to problem solving that embraces complexity, multiplicity of actors, processes, ideas and solutions. Deleuze and Guattari conceptualize and alternative to the hierarchical 'arborescent model' as that of the 'rhizome', "unlike trees or their roots, the rhizome connects any point to any other point, and its traits are not necessarily linked to traits of the same nature...a rhizome has no beginning or end; it is always in the middle, between things, interbeing, intermezzo. The tree imposes the verb 'to be,' but the fabric of the rhizome is the conjunction, 'and...and...and'"' (Deleuze \& Guattari, 2004, pp. 23-27). In this way, a rhizomatic process becomes a methodology to expand the process of design and production as an evolution over time. Hierarchical design processes create boundaries, whereas rhizomatic design processes create and expand collab- 
orative networks. As David Harvey (2012) emphasizes, fundamental and radical re-shaping of the city requires a collective power.

To reconfigure the role of design in the production of space would seek to enable a collective power, a counterweight to currently unequal process of development, rather than accepting what McDonough calls a strategy of tragedy which only makes the bad seem less bad (McDonough \& Braungart, 2010). Designers must resist becoming complicit in translating the needs of the community into professional representations of space that reinforce existing power structures. Creating spaces of potentiality and difference instead captures design's ability to redistribute power. Resisting hegemonic processes requires recognizing "other spaces of knowledge production...to enfranchise other spatial rationalities" (Lu, 2012, p. 241) and shifting the role of professionals "to design infrastructure into which citizens literally add their own programmes, labour, materials, and aesthetic. Here, high and low taste-cultures, static and dynamic processes, professionals and laymen all mix to produce a complex yet highly organized landscape" (Salomon, 2012, p. 441).

A lack of theorization around this type of dynamic design and planning practice results in examples such as placemaking, which merely seek to increase community participation without reconceptualizing the process by which space is produced. New and different forms of "participation" have been hot topics in design and planning professions recently, which we recognize as a positive change from more modernist perspectives of the all-knowing professional decreeing designs from above. However, these types of participation do not go nearly far enough. They are often co-opted by designers, planners, and developers to tick boxes and sell their products (Jones et al., 2005). As a result these processes of participation, and their products, often fail users and other actors. Co-production is more than talking to or consulting with stakeholders. Coproduction can be imagined as if the user or community member were an equal partner in the design process. This may seem counter intuitive to trained designers and planners, however, if imagined in terms of knowledge and expertise, the designers possess the professional knowledge of site analysis, the creative process, and structural design, but the community or user possess unequalled knowledge of the spaces and places they occupy. Granted, this knowledge is sometimes obscured by both its simplicity and complexity, which illustrates the need for professional design expertise to co-productively participate in the analysis of spatial usage, interaction, peculiarities, and meaning. By capitalizing on these equally important types of expertise both designers and users can benefit. Designers and planners should consider even more factors in their co-productive practice, beyond the user, participants in the process of space can be various elements of environment, technology, and material, which influence not only the reality and physicality of space, but also how it will be interacted with by each participant in the spatial process and thus each iteration of the space's dynamic future.

Heynen (2013) discusses different ways in which the dialogue between spatial form and social processes are negotiated and presents ways in which they can be conceptually understood. He points out that the spatial disciplines understand (and misunderstand) this elusive relationship from discrepant perspectives, methodologies and objectives. In addition to finding commonalities and closer collaboration between the spatial disciplines, the creation of spaces of potentiality seeks to assimilate both methodologies of social processes and professional design processes.

\section{Co-Producing Spaces of Potentiality and Difference}

The purpose of space is not to be fixed or finished, space is a constantly evolving thing and its production a constantly moving process, as influenced by its many inputs. Designers should consider this in the analysis of people and spaces as well as in designing with them, they should endeavor to co-produce space that responds to these inputs and participates in this dynamism instead of serving as both an ideological and physical obstacle. Instead, the role of the designer or planner is to facilitate the continuation of the feedback loop of spaces of potentiality and spaces of difference, which can be constantly evaluated and managed through architectural autogestion. This can make real the spaces of potentiality and difference.

Co-producing spaces of potentiality and difference is an effort to further the closure of the gap between the design and planning professions and their understanding of the production of space as a larger scale process. It is necessary to further develop the theorization and methodologies of co-productive practice. Not only do we contend that this would allow the "current" intended use of the space to flourish, but we also contend that as the space transforms into the many versions of itself in the future it will be malleable enough to serve the shifting purposes.

\section{Acknowledgments}

The authors acknowledge the support of the Manchester Architecture Research Centre, The University of Manchester, and The Bartlett Development Planning Unit, University College London. We thank our colleague Colleen Hiner, for her comments on an earlier draft of this manuscript.

\section{Conflict of Interests}

The authors declare no conflict of interests. 


\section{References}

Agamben, G. (2007). The coming community. Minneapolis, MN: University of Minnesota Press.

Agamben, G. (2010). Nudities. Stanford, CA: Stanford University Press.

Agamben, G., \& Heller-Roazen, E. (1999). Potentialities: Collected essays in Philosophy. Stanford, CA: Stanford University Press.

Awan, N., Schneider, T., \& Till, J. (2011). Spatial agency. London: Routledge.

Brenner, N., \& Elden, S. (2009). State, space, world selected essays Henri Lefebvre. Minneapolis, MN: University of Minnesota Press.

Brenner, N., Marcuse, P., \& Mayer, M. (2012). Cities for people, not for profit: An introduction. In N. Brenner, P. Marcuse \& M. Mayer (Eds.), Cities for people, not for profit: Critical urban theory and the right to the city (pp. 1-10). London: Routledge.

Cooke, B., \& Kothari, U. (2001). The case for participation as tyranny. In B. Cooke \& U. Kothari (Eds.), Participation: The new tyranny? (pp.1-15). London: Zed Books.

Deleuze, G., \& Guattari, F. (2004). A thousand plateaus: Capitalism and Schizophrenia. London: Continuum

Elden, S. (2004). Understanding Henri Lefebvre. London: Bloomsbury.

Harvey, D. (2012). Rebel cities: From the right to the city to the urban revolution. London: Verso.

Heynen, H. (2013). Space as receptor, instrument or stage: Notes on the interaction between spatial and social constellations. International Planning Studies, 18(3-4), 342-357.

Jenkins, P., \& Forsyth, L. (2010). Architecture, participation and society. London: Routledge.

Jones, P. B., Petrescu, D., \& Till, J. (2005). Architecture and participation. New York: Spon Press.

Lefebvre, H. (1976). De l'état, II: Theorie marxiste de l'état de Hegel a Mao. Paris: Union Generale d'Editions.

Lefebvre, H. (1991). The production of space. Oxford, UK: Blackwell. (Original work published 1974)

Lefebvre, H. (2003). The urban revolution, Minneapolis, MN: University of Minnesota Press. (Original work published 1970)

Lefebvre, H. (2009). Theoretical problems of autogestion In N. Brenner \& S. Elden (Eds.), State, space, world: Selected essays (pp. 138-152). Minneapolis: University of Minnesota Press. (Original work published 1966)

Lefebvre, H. (2009). Comments on a new state form. In N. Brenner \& S. Elden (Eds.), State, space, world: Selected essays (pp. 124-137). Minneapolis, MN: University of Minnesota Press. (Original work published 1979)
Lefebvre, H. (2009). Space and the state. In N. Brenner \& S. Elden (Eds.), State, space, world: Selected essays (pp. 254-258). Minneapolis, MN: University of Minnesota Press. (Original work published 1978)

Lu, D. (2012) Entangled modernities in architecture. In C. G. Crysler, S. Cairns \& H. Heynen (Eds.), The SAGE handbook of architectural theory (pp. 231-246). London: SAGE.

McDonough, W., \& Braungart, M. (2010). Cradle to cradle: Remaking the way we make things. London: MacMillan.

Merrifield, A. (1993). Place and space: A Lefebvrian reconciliation. Transactions of the Institute of British Geographers, 18(4), 516-531.

Merrifield, A. (2006). Henri Lefebvre: A critical introduction. London: Routledge.

Milgrom, R. (2008). Lucien Kroll: Design, difference, everyday life. In K. Goonewardena, S. Kipfer, R. Milgrom \& C. Schmid (Eds.), Space, difference, everyday life: Reading Henri Lefebvre (pp. 27-45). London: Routledge.

Peet, R., \& Hartwick, E (2009). Theories of development: Contentions, arguments, alternatives (2nd ed.). New York: The Guilford Press

Project for Public Spaces (2015). What is placemaking? Project For Public Spaces. Retrieved from www.pps. org/reference/what_is_placemaking

Rist, G. (2006). Before thinking about what next: Prerequisites for alternatives. Development Dialogue, 1(47), 65-96.

Salomon, D. (2012). Plural profession, discrepant practices. In C. G. Crysler, S. Cairns \& H. Heynen (Eds.), The SAGE handbook of architectural theory (pp. 430442). London: SAGE.

Schmid, C. (2008). Henri Lefebvre's theory of the production of space: Towards a three-dimensional dialectic. In K. Goonewardena, S. Kipfer, R. Milgrom \& C. Schmid (Eds.), Space, difference, everyday life: Reading Henri Lefebvre (pp. 27-45). London: Routledge.

Stanek, L. (2008). Space as concrete abstraction: Hegel, Marx, and modern urbanism in Henri Lefebvre. In K. Goonewardena, S. Kipfer, R. Milgrom \& C. Schmid (Eds.), Space, difference, everyday life: Reading Henri Lefebvre (pp. 62-79). London: Routledge.

Stanek, L. (2011). Henri Lefebvre on space: Architecture, urban research, and the production of theory. Minneapolis, MN: University of Minnesota Press.

Till, J. (2009). Architecture depends. Cambridge, MA: MIT Press.

Wolch, J., Pincetl, S., \& Pulido, L. (2001). Urban nature and the nature of urbanism. In M. Dear \& J. Dallas Dishman (Eds.), From Chicago to L.A.: Making sense of urban theory (pp. 367-402). London: Sage. 
About the Authors

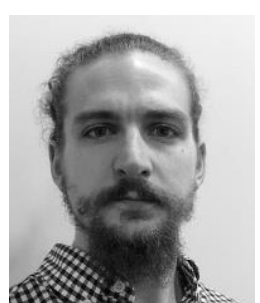

\section{Garrett Wolf}

Garrett Wolf is a Doctoral Researcher in the Manchester Architecture Research Centre at The University of Manchester. He is a designer and urban scholar whose research interests include the intersection of everyday life and design, co-production, urban sustainability, and post-Soviet urbanism. His doctoral research examines urban transformations in Uzbekistan. He holds a BLA in Landscape Architecture, and a BA and MA in Geography from Louisiana State University.

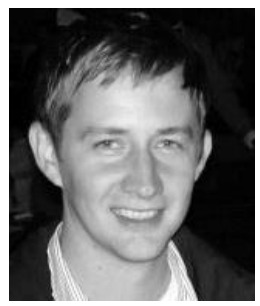

\section{Nathan Mahaffey}

Nathan Mahaffey is a designer, researcher and development planner. Current interests explore alternative strategies for design as an emancipatory process. Professional experience includes 10 years in architecture, community-based design, planning and research in Latin America, the Middle East, Southeast Asia and the United States. He received a B.Arch from Louisiana State University and an MSc in Building \& Urban Design in Development from The Bartlett Development Planning Unit. 